\title{
High incidence of multidrug-resistant fecal E. coli producing ESBLS and carried ST131 in Jordanian adults
}

\author{
Reham Muin Abu Sneineh ${ }^{1}$, Azmi Mahafzah ${ }^{1}$, \\ Nayef Abdallat ${ }^{2}$, Asem Shehabi ${ }^{1}$
}

\section{Abstract}

Background: Escherichia coli is part of the normal human intestinal microflora, although it has the potential of causing a variety of invasive and diarrheal diseases. It is also a frequent cause of community- and hospital-acquired urinary tract infections. Intestinal E. coli has the potential to rapidly develop multidrug resistant (MDR) and to emerge as extended-spectrum $\beta$-lactamases (ESBLs)-producer.

Methods: Over the period of July through November, 2015; 287 stool samples were collected from Jordanian adults who visited the students' clinic of the University of Jordan. Fecal samples were collected and cultured for isolation of $E$. coli. The isolates were investigated for antimicrobial susceptibility, and molecular method of polymerase chain reaction (PCR) was performed for the detection genes of ST131 clone, blaCTX-M group I, blaCTX-M-15, blaNDM-1, blaVIM, blaIMP, blaOXA-48, blaKPC and fluoroquinolones resistance (gyrA and parC).

Results: A total of 105/287 E. coli isolates (36.6\%) were found to be MDR to at least 3 classes of antibiotics, of these $45.1 \%$ were ESBLproducers. A total of 51 representative MDR isolates indicated the following; 49\% were found positive for ST131 clone, 58.8\% were resistant for ciprofloxacin, and $41.2 \%$ were positive for CTX-M group I and CTX-M-15, respectively. All these MDR isolates were also positive for mutated both gyrA and parC genes, and only $6 / 51$ isolates (11.8\%) were positive for each blaNDM-1 and blaKPC. One out of 51 MDR isolates (2\%) was positive for blaVIM, and none of these isolates was positive for blalMP nor blaOXA-48 genes.
1 Department of Pathology-Microbiology, School of Medicine, The University of Jordan, Amman, Jordan.

2 The University of Jordan-Students Clinic, Amman, Jordan

Contact information:

Prof. Asem A. Shehabi.

$\equiv$ ashehabi@ju.edu.jo asashehabi2@gmail.com 
Conclusion: This study indicated that a relatively high rates of commensal fecal $E$. coli isolates from Jordanian adults were MDR, ESBLsproducer and belonging to ST131 clone. Also, high rates of CTX-M-15 and fluoroquinolones resistance were found among MDR E. coli isolates.

\section{Keywords}

Fecal E.coli ST131; Antimicrobial Resistance; ESBls; Jordanian Adults.

\section{Introduction}

The increased incidence of ESBLs, that make Gramnegative bacteria frequently resistant to penicillins, cephalosporins and aztreonam by hydrolyzing them, is becoming a global health problem [1].

Class of CTX-M type enzymes are the most prevalent extended-spectrum $\beta$-lactamases (ESBLs) worldwide including Arab Middle East countries [2, 3]. Among the CTX-M type enzymes, CTX-M-15 has been frequently found in Arab countries over the last decade [3-7].

Carbapenems are part of the last line of defense against serious or invasive infections caused by extremely drug-resistant Gram-negative pathogens producing ESBLs [8-9].

Prior to the last decade, carbapenem resistance in Enterobacteriaceae was rare. However, KlebsieIla pneumonia carbapenemase (KPC), New Delhi metallo- $\beta$-lactamase-1 (NDM-1), and recently oxacillinase-48 (OXA-48) have been reported in Enterobacteriaceae isolates [10].

E. coli species are currently classified into four main phylogenetic groups (A, B1, B2, and D), where $A$ and $B 1$ groups are mainly commensal strains, whereas extraintestinal pathogenic strains are mostly part of B2 and D groups. The clone that belong to the B2 phylogenetic subgroup I, characterized by the multilocus sequence type (MLST) 131 and exhibits a specific 025 type (O25b) [11].
This new discovered ST131 clone has been recently isolated from a diverse range of infections caused in community and hospitalized patients across the world, and it has been found as ESBL CTX$\mathrm{M}$-15-producer with a high virulence potential. In addition, ST131 clone has been reported to cause major infection complications from cystitis to lifethreatening sepsis in many countries [4, 12-14]. Fluoroquinolones and trimethoprim are no longer effective for empiric therapy of $E$. coli ST131 infections [13-16].

This study investigated the occurrence rate of ESBLs, especially metallo- $\beta$-lactamases and ST131 clone among $E$. coli colonized intestines of Jordanian adults.

\section{Population and Methods}

\section{Subjects and data collection}

A total of 287 feces samples using wet sterile cotton swab immersed in $3 \mathrm{ml} 0.85 \%$ sterile normal saline tube had been collected from students (one sample from each person) whom age ranged between 18 to 35 years old visiting the University of Jordan Students' Clinic in the period from July 2015 to November 2015. Samples were transported within few hours to the microbiology research lab for culture and further investigation. 
The biographic data for each student was obtained and registered on a prepared sheet which included the following: name, gender, age, university number, presence of infection and history of antibiotic treatment during the last 6 months before sampling their stool (Table 2).

\section{Culture and identification of E. coli}

All collected swabs were cultured directly on MacConkey agar and incubated for 24 hours in $37^{\circ} \mathrm{C}$. Five colonies that morphologically represent $E$. colilike growth were selected from MacConkey culture plates and sub-cultured on MacConkey again to obtain pure $E$. coli isolates. Lactose-fermenter pure growth on sub-culture plates were confirmed to be E. coli by standard biochemical tests, including citrate utilization, lactose and glucose fermentation on Kligler iron agar tubes, urease and indole production. All confirmed cultures of $E$. coli isolates were stored in cryotubes that contain Mueller-Hinton agar with 15\% glycerol and were stored at -70 ${ }^{\circ} \mathrm{C}$. E. coli isolates were later used for antimicrobial susceptibility test, DNA extraction and polymerase chain reaction $(P C R)$ tests.

\section{Antimicrobial susceptibility testing}

$E$. coli isolates were tested using antimicrobial susceptibility disc diffusion method according to the recommendation of the Clinical Laboratory and Standards Institute (CLSI) 2015 [17]. The results were interpreted according to the breakpoints of tested antibiotics as recommended in CLSI 2015 guidelines. E. coli ATCC ${ }^{\circledR} 25922$ (ATCC ${ }^{\circledR}$ is a registered trademark of the American Type Culture Collection) was used as control strain. Minimum inhibitory concentration (MIC) using E-test were used for testing MDR E. coli isolates (Multi-drug resistant; which are resistant to at least 3 classes of antibiotics) including resistant for ciprofloxacin and carbapenemase. The results of susceptibility tests were interpreted according to the guidelines of CLSI.

\section{Extraction of DNA}

E. coli isolates stored in cryotubes at $-70^{\circ} \mathrm{C}$ were thawed at room temperature and cultured onto MacConkey agar. After incubation at $37^{\circ} \mathrm{C}$ for 24 hours, a few colonies were picked from the agar, inoculated into Mueller-Hinton broth and incubated at $37^{\circ} \mathrm{C}$ for 18 hours (overnight). Then, the bacterial DNA was extracted using the Wizard genomic DNA Purification Kit, Promega, (USA) following manufactures instructions. DNA extracted for each $E$. coli isolate was quantified to ensure that it is significant for PCR (Concentration $>50 \mathrm{ng} / \mu \mathrm{L}$ ), with a purity at $A 260 / A 280=1.6-1.8$, using Thermo Scientific NanoDrop 1000 Spectrophotometer.

\section{Detection of ESBLs, KPC and ST131}

E. coli isolates in cryotubes stored at $-70^{\circ} \mathrm{C}$ were thawed at room temperature, and cultured onto MacConkey agar. After incubation at $37^{\circ} \mathrm{C}$ overnight few colonies were picked from the agar, and inoculated into $3 \mathrm{ml}$ Luria Broth (LB) and incubated for 24 hours at $37^{\circ} \mathrm{C}$. The bacterial plasmid was extracted using the Zyppy ${ }^{\top \mathrm{M}}$ Plasmid Miniprep Kit, Zymo (USA) according to manufacturer's instructions. Plasmid extraction was done for the identification of plasmid encoded $\beta$-lactamases genes (blaCTX-M group I, blaCTX-M-15, blaKPC, blaNDM-1, blaOXA-48, blalMP and blaVIM). All Primer targets, sequences, product size and their references are shown in Table 1. The following controls strains were used: K. pneumonia (ATCC BAA-1705), K. pneumoniae ATCC BAA-2146; CMUL E. coli CL 502; CMUL $P$. aeruginosa 132, CMUL $P$. aeruginosa 123, obtained from Prof Monzer Hamza, Laboratoire Microbiologie Santé et Environnement (LMSE), Ecole Doctorale des Sciences et de Technologie, Faculté de Santé Publique, Université Libanaise, Tripoli, Lebanon).

\section{Agarose gel preparation for gel electrophoresis}

Tris Base EDTA (TBE) 1X buffer was prepared; by one part of stock solution $10 \mathrm{X}$ with nine parts of 
Table 1. Primer targets, sequences, product sizes and references, positive control strains used in the study.

\begin{tabular}{|c|c|c|c|c|}
\hline Target genes & Primer sequence & $\begin{array}{l}\text { Product } \\
\text { size(bp) }\end{array}$ & Autor & Year \\
\hline CTX-M group-1 & $\begin{array}{l}\text { M13U (5'GGTTAAAAAATCACTGCGTC-3' ) } \\
\text { M13L (5'-TTGGTGACGATTTTAGCCGC- 3' ) }\end{array}$ & 863 & Leflon-Guibout & 2004 \\
\hline$C T X-M-15$ & $\begin{array}{l}\text { F-CTX-M-F1 (5'ATAAAACCGGCAGCGGTG-3') } \\
\text { R-CTX-M-F2 (5'-GAATTTTGACGATCGGGG-3') }\end{array}$ & 483 & Leflon-Guibout & 2004 \\
\hline ParC & $\begin{array}{l}\text { F (5'-CGATTGCCGCCTGAGCCACTT-3') } \\
\text { R (5'-GCGAATAAGTTGAGGAATCAG-3') }\end{array}$ & 605 & Leflon-Guibout & 2004 \\
\hline gyrA & $\begin{array}{l}\text { F (5'-CGACCTTGCGAGAGAAAT-3') } \\
\text { R (5'-GTTCCATCAGCCCTTCAA-3') }\end{array}$ & 625 & Leflon-Guibout & 2004 \\
\hline$K P C$ & $\begin{array}{l}\text { F (5'-ATGTCACTGTATCGCCGTCT- 3') } \\
\text { R (5'-TTACTGCCCGTTGACGCCCA-3') }\end{array}$ & 880 & Pillai & 2009 \\
\hline VIM & $\begin{array}{l}\text { F (5'-GTTTGGTCGCATATCGCAAC-3') } \\
\text { R (5'-AATGCGCAGCACCAGGATAG-3') }\end{array}$ & 382 & Pitout & 2005 \\
\hline IMP & $\begin{array}{l}\text { A (5'-GAAGGCGTTTATGTTCATAC-3') } \\
\text { B (5'-GTACGTTTCAAGAGTGATGC-3') }\end{array}$ & 587 & Pitout & 2005 \\
\hline$N D M-1$ & $\begin{array}{l}\text { F (5'-GGTGCATGCCCGGTGAAATC-3') } \\
\text { R (5'-ATGCTGGCCTTGGGGAACG-3') }\end{array}$ & 660 & Bonnin & 2012 \\
\hline OXA-48 & $\begin{array}{l}\text { A (5'- TTGGTGGCATCGATTATCGG-3') } \\
\text { B (5'-GAGCACTTCTTTTGTGATGGC-3') }\end{array}$ & 743 & Poirel & 2004 \\
\hline $\operatorname{trpA}$ & $\begin{array}{l}\text { F (5'-GCTACGAATCTCTGTTTGCC-3') } \\
\text { R (5'-GCAACGCGGCCTGGCGGAAG-3') }\end{array}$ & 427 & Clermont & 2009 \\
\hline pabB & $\begin{array}{l}\text { F (5'-TCCAGCAGGTGCTGGATCGT-3') } \\
\text { R (5'-GCGAAATTTTTCGCCGTACTGT-3') }\end{array}$ & 347 & Clermont & 2009 \\
\hline
\end{tabular}

distilled water. The agarose gel at concentration of $2 \%$ was prepared by dissolving 3.6 gram of agarose powder in $180 \mathrm{ml}$ of $1 \mathrm{X}$ buffer and boiling in microwave until agarose completely dissolved, then $8 \mu$ of ethidium bromide $(10 \mathrm{mg} / \mathrm{ml})$ was added. The agarose was poured into the electrophoresis tray and left to solidify at room temperature for 20 minutes. After removal of coombs and gates, the gel placed in the electrophoresis tank pre-filled with $1 \mathrm{X}$ TBE buffer to be loaded with PCR products.

\section{Statistical analysis}

Data were analyzed using Statistical Package for Social Sciences (IBM SPSS) version 21. The level of significance was set at a $P$ value of $\leq 0.05$ to test the hypothesis of no association.

\section{Results}

A total of 287 fecal samples were obtained from adult students. Of these samples, 88 were males (30.7\%) with average age $21.56 \pm 2.26$ years and 199 (69.3\%) were females with average age $21.8 \pm$ 3.32 years (Table 2 ). The antimicrobial susceptibility pattern of 287 E. coli isolates is shown in Table $\mathbf{3}$.

Table 2. Demographic characteristics of 287 adults whose fecal samples were cultured for $E$. coli isolates*.

\begin{tabular}{|c|c|c|c|c|c|c|}
\hline \multirow{2}{*}{ Characteristics } & \multicolumn{2}{|c|}{ Male } & \multicolumn{2}{|c|}{ Females } & \multicolumn{2}{|c|}{ Total no } \\
\hline & No. & $\%$ & No. & $\%$ & No. & $\%$ \\
\hline Age (years) & 88 & 30.7 & 199 & 69.3 & 287 & 100 \\
\hline Mean \pm SD & \multicolumn{2}{|c|}{$21.58 \pm 2.26$} & \multicolumn{2}{|c|}{$21.80 \pm 3.32$} & & \\
\hline $\begin{array}{l}\text { Age-range } \\
\text { (years) }\end{array}$ & \multicolumn{2}{|c|}{$18-34$} & \multicolumn{2}{|c|}{$18-35$} & & \\
\hline \multicolumn{7}{|c|}{$\begin{array}{l}\text { *: The majority of students visited the clinical for treatment of respiratory } \\
\text { tract infection. About one third of the students have stated that they have } \\
\text { taken antibiotics during the } 6 \text { months before sampling their stools. }\end{array}$} \\
\hline
\end{tabular}


Table 3. Antimicrobial susceptibility patterns of 287 E. coli isolates*

\begin{tabular}{|l|c|c|}
\hline \multirow{2}{*}{ Antimicrobial drug } & \multicolumn{2}{|c|}{ resistant isolates } \\
\cline { 2 - 3 } & No. & $\%$ \\
\hline Ampicillin & 141 & 49.1 \\
\hline Cefuroxime & 139 & 48.4 \\
\hline Nalidixic acid & 126 & 44 \\
\hline Tetracycline & 124 & 43.2 \\
\hline Co-trimoxazole & 97 & 33.1 \\
\hline Cefotaxime & 46 & 16 \\
\hline Ciprofloxacin & 41 & 14.3 \\
\hline Gentamicin & 24 & 8.4 \\
\hline Ceftazidime & 22 & 7.6 \\
\hline Imipenem & 17 & 5.9 \\
\hline Amikacin & 03 & 1 \\
\hline \multicolumn{1}{|c|}{ *: 105 of E. coli isolates (36.6\%) were considered as MDR(resistant for at least 3 } \\
\hline
\end{tabular}

Table 4. Minimum inhibitory concentration range with MIC50 and MIC90 for three tested antibiotics*.

\begin{tabular}{l|c|c|c|c|}
$\begin{array}{l}\text { Antimicrobial } \\
\text { drug }\end{array}$ & MIC50 & MIC90 & $\begin{array}{c}\text { MIC } \\
\text { Range }\end{array}$ & $\begin{array}{c}\text { Breakpoints } \\
\text { for } \\
\text { susceptible }\end{array}$ \\
\hline Ciprofloxacin & $\mu \mathrm{g} / \mathrm{mL}$ & $\mu \mathrm{g} / \mathrm{mL}$ & $\mu \mathrm{g} / \mathrm{mL}$ & $\mu \mathrm{g} / \mathrm{mL}$ \\
\hline Imipenem & 0.9 & 17.8 & $0.002-32$ & $\leq 0.06$ \\
\hline Meropenem & 0.1 & 0.17 & $0.002-32$ & $\leq 1$ \\
\hline & & 0.05 & $0.002-32$ & $\leq 1$ \\
\hline
\end{tabular}

Minimum inhibitory concentrations (MICs) of Multiple Drug Resistant (MDR) E. coli and the MIC ranges for three tested antibiotics (ciprofloxacin, imipenem and meropenem) are given in Table 4. The distribution of genes for $E S B L S$, quinolone-resistance, and ST131 clone among 51 MDR representative E. coli isolates are demonstrated in Table $\mathbf{5}$.

\section{Sequencing results for ST131 strains}

Three randomly picked positive E. coli ST131 isolates were sent for sequencing to Genewiz company, USA. The sequencing results were analyzed by using
Table 5. Distribution of ESBLS genes, quinoloneresistance, and ST131 among 51 representative MDR E. coli isolates*.

\begin{tabular}{|c|c|c|}
\hline \multirow{2}{*}{ Specific genes } & \multicolumn{2}{|c|}{ Positive E. coli isolates } \\
\hline & No. & $\%$ \\
\hline blaCTXM group-I & 30 & 58.8 \\
\hline blaCTXM-15 & 21 & 41.2 \\
\hline blaKPC & 6 & 11.8 \\
\hline blaNDM-1 & 6 & 11.8 \\
\hline blaVIM & 1 & 2.0 \\
\hline blalMP & \multicolumn{2}{|c|}{ Null } \\
\hline blaOXA-48 & \multicolumn{2}{|c|}{ Null } \\
\hline ParC & 51 & 100 \\
\hline gyrA & 51 & 100 \\
\hline ST131 & 25 & 49 \\
\hline
\end{tabular}

*: Resistant isolates to at least antibiotic classes (ampicillin, cotrimoxazole, cefuroxime).

the website http://www.ecogene.org/gene. Interrogation of the gene database registered sequences with identity homologies were between 98-99\% for pabB in three isolates.

\section{Discussion}

This study investigated antibiotic resistance profiles for 287 E. coli isolates from fecal samples of adults visiting the students' clinic of the University of Jordan. The study found that $36.6 \%$ (105) of these students carried MDR fecal $E$. coli for at least 3 classes of antibiotics. E. coli ESBL-producers were found to be $45.1 \%$ among 105 MDR tested isolates. These results are similar to two recent studies examined fecal samples from hospitalized and out-patient infants admitted to the Pediatric Clinic at JUH during the years 2011 to 2014, and both studies reported rates of $30.6 \%$ and $42 \%$ MDR E. coli isolates which were ESBL-producers $[4,6]$.

The emergence of antimicrobial resistance is becoming a serious global health problem worldwide, especially among pathogenic $E$. coli $[1,23]$. Most 
published data on antimicrobial resistance were obtained from hospitalized or out-patients. Few studies have investigated the occurrence of antimicrobial resistance in a community population. Healthy individuals may carry MDR fecal E. coli, and these individuals can spread their resistant $E$. coli in their community, and might be a potential source of community infections [24].

A recent study, which was carried at the same period in four medical centers in Jordan and Lebanon over the period between 2011 and 2013, and included samples from patients have UTI and intra-abdominal infection (IAI), has shown that ESBL-producers among E. coli isolates were 43\% and $49 \%$ in UTI and IAI samples, respectively [26]. A Libyan study investigated 333 Enterobacteriaceae isolates from both patients and healthy controls, and found only 15 (4.5\%) isolates were positive for ESBL using the double disc synergy test. The Libyan study also detected that patients were infected with $5.4 \%$ of $E$. coli and $11.4 \%$ of K. pneumoniae isolates which were ESBL-producers. Additionally, the study indicated that almost all the ESBL-producing isolates were consistently more resistant to a wide variety of antimicrobial agents than the non-ESBL-producers as it is the case in our study [27]. The low incidence of ESBLproducers in the Libyan study may be due to use a detection test which is not sensitive enough like molecular detection using PCR which was applied in our study and often in other studies. Other recent studies from the Arab Middle East region documented that rates of E. coli ESBL-producers remain higher in clinical samples when compared to healthy persons $[5,28]$.

This study showed a relatively high percentage of blaCTX-M group I and blaCTX-M-15 among the MDR E. coli isolates $(58.8 \%$ and $41.2 \%$, respectively). It has been previously documented that blaCTX-M-15 group is widely prevalent in Arab Middle East region [3-7]. Currently, blaCTX-M-15 type is commonly detected in ESBL positive Enterobacteria- ceae and others Gram-negative pathogens through the whole world [2, 29].

This study also demonstrated presence of different $\beta$-lactamases other than CTX-M types such as KPC, NDM-1 which had been detected in $11.8 \%$, and VIM in $2 \%$ of MDR isolates, while no detection of IMP and OXA-48 was recognized (Table 5). These results are novel, since no previous study in Jordan has reported on the occurrence of KPC, NDM-1 $\beta$-lactamases in $E$. coli isolates from any source.

This study detected ParC and gyrA quinoloneresistance genes among all $51 \mathrm{MDR} E$. coli isolates. This high percentage may indicate extensive consumption of fluoroquinolones in Jordan according to our available information. Another suspected factor which may contribute to high fluoquinolone-resistance is the dissemination of ST131 E. coli clone $[4,30]$. The present study shows that $E$. coli ST131 clone carrying the $p a b B$ gene and ciprofloxacin-resistant was accounted for $49 \%$ of MDR $E$. coli isolates. This result is relatively high when compared to a recent study investigated fecal $E$. coli isolates from Jordanian infants admitted to the $\mathrm{JUH}$, and found only 9 isolates (7.2\%) to be positive for ST131 clone [4]. A study in US found that ST131 accounted for $46 \%$ of ESBL-positive E. coli isolates [30]. Other studies from developed countries reported on the emergence of $E$. coli ST131 types in geriatric patients and among hospitalized patients colonized intestinally with fluoroquinolone-resistant E. coli. [30-32]. In addition, a recent paper from Japan, found Type 131 C1-M27 subclone, among ESBL-Producing E. coli in wastewater [33].

This study suggests that continuous increasing incidence of $E$. coli producing ESBL and fluoquinoloneresistance in intestinal tract of population would make the treatment of infections caused by E. coli, especially community UTIs more difficult and challenging. 


\section{Acknowledgement}

This study has been supported financially by the Dean of Research, the University of Jordan.

\section{Ethical considerations}

This study has been approved by the Faculty of Medicine and the Faculty of Graduate studies, University of Jordan. Also, permission was obtained from the Institutional Review Board (IRB) and Ethical Committee at Jordan University Hospital (Permission No. 22/2015)

\section{References}

1. Antimicrobial resistance global report on surveillance, World Health organization, 2014 (ISBN 978924156474 8) 20, 1211 Geneva 27, Switzerland,

2. CantÓn R, Gonzalez-Alba JM, Galan JC. CTX-M enzymes: origin and diffusion. Front Microbiol 2012; 3: 110.

3. Baroud M, Araj GF, Matar GM. Spread of CTX-M-15 Extended Spectrum $\beta$-Lactamases Encoding Genes Among Enterobacteriaceae in the Middle Eastern Region. The IAJAA 2011; 1(1): 4.

4. Badran EF, Qamar Din AR, Shehabi AA. Low intestinal colonization of Escherichia coli clone ST131 producing CTX-M-15 in Jordanian infants. J Med Microbiol 2016; 65(2): 137-141.

5. Tayh G, Ben Sallem R, Ben Yahia H, Gharsa H, Klibi N. et al. First report of extended-spectrum $\beta$-lactamases among clinical isolates of Escherichia coli in Gaza Strip, Palestine. J Glob Antimicrob Resist 2016; 6: 17-21.

6. Abu Salah MA, Badran, EF, Shehabi AA. High incidence of multidrug resistant Escherichia coli producing CTX-M-type ESBLs colonizing the intestine of Jordanian infants. The IAJAA 2013; 3(4): 3.

7. Al-Agamy MHM, Ashour MSE, Wiegand I. First description of CTX-M $\beta$-lactamase-producing clinical Escherichia coli isolates from Egypt. Int J Antimicrob Agents 2006; 27(6): 545-548.

8. Nordmann P. Rapid evolution and spread of carbapenemases among Enterobacteriaceae in Europe. Clin Microbiol Infect 2012; 18(5): 413-431.

9. Bush Karen. Bench-to-bedside review: The role of $\beta$-lactamases in antibiotic resistant Gram-negative infections. Crit Care 2010;14(3): 224.

10. Patel G, Bonomo RA. (2013), "Stormy waters ahead": global emergence of carbapenemases. Front Microbiol 2013; 4:8.

11. Can F, Azap OK, Seref C, Ispir P,Arslan H, Ergonul O. Emerging Escherichia coli O25b/ ST131 clone predicts treatment failure in urinary tract infections. Clin Infect Dis 2015; 60(4): 523-527.
12. Papagiannitsis CC, Studentova $V$, Jakubu $V$, Spanelova $P$, Urbaskova P, et al. High prevalence of ST131 among CTX-Mproducing Escherichia coli from community-acquired infections, in the Czech Republic. Microb Drug Resist 2015; 21(1): 74-84.

13. Dahbi G, Mora A, Mamani R, Lopez C, Alonso MP, et al. Molecular epidemiology and virulence of Escherichia coli O16:H5-ST131: comparison with $\mathrm{H} 30$ and H30-Rx subclones of O25b: H4-ST131. Int Med Microbiol 2014; 304 (8): 1247-1257.

14. $\mathrm{Wu}, \mathrm{YH}$, Cheng MF, Lai $\mathrm{CH}$, Lin $\mathrm{HH}$, Hung $\mathrm{CH}$, et al. The role of Sequence Type (ST) 131 in adult community-onset non-ESBLproducing Escherichia coli bacteraemia. BMC Infect Dis 2014; 14: 579.

15. Banerjee R, Johnston B, Lohse C, Porter SB, Clabots C, et al. Escherichia coli Sequence Type 131 Is a Dominant, AntimicrobialResistant Clonal Group Associated with Healthcare and Elderly Hosts. Infect Control Hosp Epidemiol 2013; 34(4): 361-369.

16. Clermont O, Dhanji H, Upton M, Gibreel T, Fox A, et al. Rapid detection of the O25b-ST131 clone of Escherichia coli encompassing the CTX-M-15-producing strains. J Antimicrob Chemother 2009; 64(2): 274-277.

17. Clinical and Laboratory Standards Institute. Performance Standards for Antimicrobial Susceptibility Testing; TwentyFifth Informational Supplement. CLSI document M100-S25 (ISBN 1-56238-989-0 [Print]; ISBN 1-56238-990-4 [Electronic]). Clinical and Laboratory Standards Institute, 950 West Valley Road, Suite 2500, Wayne, Pennsylvania 19087 USA, 2015.

18. Leflon-Guibout V, Jurand C, Bonacorsi S, Espinasse F, Guelfi MC, et al. Emergence and Spread of Three Clonally Related Virulent Isolates of CTX-M-15-Producing Escherichia coli with Variable Resistance to Aminoglycosides and Tetracycline in a French Geriatric Hospital. Antimicrob Agents Chemother 2004; 48(10): 3736-3742.

19. Pillai DR, Melano R, Rawte P, Lo S, Tijet N, et al. Klebsiella pneumoniae Carbapenemase, Canada. Emerg Infect Dis 2009; 15(5): 827-829.

20. Pitout JDD, Gregson DB, Poirel L, McClure J-A, Le $P$, et al. Detection of Pseudomonas aeruginosa Producing Metallo- $\beta$ Lactamases in a Large Centralized Laboratory. J Clin Microbiol 2005;43(7): 3129-3135

21. Bonnin RA, Naas T, Poirel L, Nordmann P. Phenotypic Biochemical, and Molecular Techniques for Detection of Metallo- $\beta$-Lactamase NDM in Acinetobacter baumanii. J Clin Microbiol 2012;50(4): 1419-1421.

22. Poirel L, Heritier C, Tolun V, Nordmann P. Emergence of Oxacillinase- Mediated Resistance to Imipenem in Klebsiella pneumonia. Antimicrob Agents Chemother 2004; 48(1): 15-22.

23. Pitout JD. Extraintestinal pathogenic Escherichia coli: a combination of virulence with antibiotic resistance. Front Microbiol 2012; 2: 9 
24. Ahmed SF, Ali MMM, Mohamed ZK, Moussa TA, Klena JD. Fecal carriage of extended-spectrum $\beta$-lactamases and AmpCproducing Escherichia coli in a Libyan community. Ann Clin Microbiol Antimicrob 2014; 13: 22.

25. Ben Sallem R, Ben Slama K, Astepa V, Jouini A, Gharsa H, et al. Prevalence and characterization of extended-spectrum betalactamase (ESBL)-producing Escherichia coli isolates in healthy volunteers in Tunisia. Eur J Clin Microbiol Infect Dis 2012; 31(7): 1511-1516.

26. Hayajneh WA, Hajj A, Hulliel F, Sarkis DK, Irani-Hakimeh N, et al. Susceptibility trends and molecular characterization of Gramnegative bacilli associated with urinary tract and intra-abdominal infections in Jordan and Lebanon: SMART 2011-2013. Int J Infect Dis 2015; 35: 56-61.

27. Shahlol AM, Abukhres OM, Taher IA. Prevalence and Characterization of Extended-Spectrum $\beta$-Lactamase-Producing Enterobacteriaceae in Brack-AlShati, Fezza, Libya. EC Microbiology 2015; 1.1: 23-32.

28. Adwan K, Jarrar N, Abu-Hijleh A, Adwan G, Awwad E. Molecular characterization of Escherichia coli isolates from patients with urinary tract infections in Palestine. J Med Microbiol 2014; 63: 229-234

29. Nicolas-Chanoine MH, Gruson C, Bialek-Davenet S, Bertrand $X$, Thomas-Jean F. et al. 10-Fold increase (2006-11) in the rate of healthy subjects with extended-spectrum $\beta$-Lactamaseproducing Escherichia coli faecal carriage in a Parisian check-up centre. J Antimicrobi Chemother 2013; 68(3): 562-568.

30. Han JH, Johnston B, Nachamkim I, Tolomero P, Bilker WB, et al. Clinical and molecular epidemiology of Escherichia coli sequence type 131 among hospitalized patients colonized intestinally with fluoroquinolone-resistant E.coli. Antimicrob Agents Chemother 2014; 58(11): 7003-7006.
31. Johnson J, Johnston B, Clabots C, Kuskowski M, Castanheira M. Escherichia coli sequence type ST131 as the major cause of serious multidrug-resistant E. coli infections in the United States. Clin Infect Dis 2010; 51(3): 286-294.

32. Ho PL, Chu YP, Wu L, Chow KH, Law PY, et al. High Prevalence of Escherichia coli sequence type 131 among antimicrobialresistant E. coli isolate from geriatric patients. J Med Microbiol 2015; 64(Pt 3): 243-247.

33. Gomi R, Matsuda T, Matsumura Y, Yamamoto M, Tanaka $M$, et al. Occurrence of Clinically Important Lineages, Including the Sequence Type 131 C1-M27 Subclone, among Extended-Spectrum- $\beta$-Lactamase-Producing Escherichia coli in Wastewater. Antimicrob Agents Chemother 2017; 61: 9 e00564-17
Publish in The International Arabic Journal of Antimicrobial Agents

The Journal is an open access peer-reviewed journal that publishes scientific papers about all aspects of antimicrobials. The journal will publish original research articles, reviews, brief reports and case reports dealing with basic and clinical antibacterial agents, antiviral, antiprotozoals, antituberculuous, antifungal and antihelminthes agents. All manuscripts must be prepared in English, and are subject to a rigorous and fair peer-review process. Accepted papers will immediately appear online. The journal aims to advance the knowledge, attitude and the research of chemotherapy in the Arabic world in cooperation with international, national scientific and public societies as well as research centers with similar aims and objectives. 